\title{
NON-HODGKIN LYMPHOMA OF THE BLADDER
}

\author{
ALBERTO A. ANTUNES, LUCIANO J. NESRALLAH, MIGUEL SROUGI \\ Division of Urology, Paulista School of Medicine, Federal University of São Paulo, UNIFESP, São Paulo, \\ SP, Brazil
}

\begin{abstract}
Lymphomas of the bladder are rare lesions, representing approximately $0.2 \%$ of the primary neoplastic lesions and approximately $1.8 \%$ of the secondary lesions in this organ.

The authors report the case of a 41-year old patient with secondary lymphoma of the bladder occurring 2 years after treatment for non-Hodgkin lymphoma, diagnosed by biopsy of cervical lymph node, and analyze the clinical and prognostic aspects of bladder lymphomas.
\end{abstract}

Key words: bladder; bladder neoplasms; lymphoma, non-Hodgkin

Int Braz J Urol. 2004; 30: 499-501

\section{INTRODUCTION}

Lymphomas of the bladder are rare lesions, representing approximately $0.2 \%$ of the primary neoplastic lesions and approximately $1.8 \%$ of the secondary lesions in this organ (1).

Patients with bladder lymphomas can be divided into 3 groups, according to their clinical presentation: 1) primary cases in bladder, 2) cases occurring in bladder as a manifestation of systemic disease, and 3) secondary cases, with clinical history of malignant lymphoma recurring in bladder. In the latter case, the main sites of primary involvement are peripheral lymph nodes, bone marrow and spleen (2).

The authors report the case of a 41-year old patient with secondary lymphoma of the bladder occurring 2 years after treatment for "non-Hodgkin" lymphoma, diagnosed by biopsy of cervical lymph node.

\section{CASE REPORT}

Male, 41-year old, asymptomatic patient was referred for urological evaluation with ultrasound revealing a tumor in the bladder lateral wall. There was a previous history of non-Hodgkin lymphoma, diagnosed through biopsy of cervical lymph node and treated with chemotherapy. Patient reported that the disease was in remission for 2 years.

An abdominal computerized tomography was performed (Figure-1), which confirmed the ultrasound

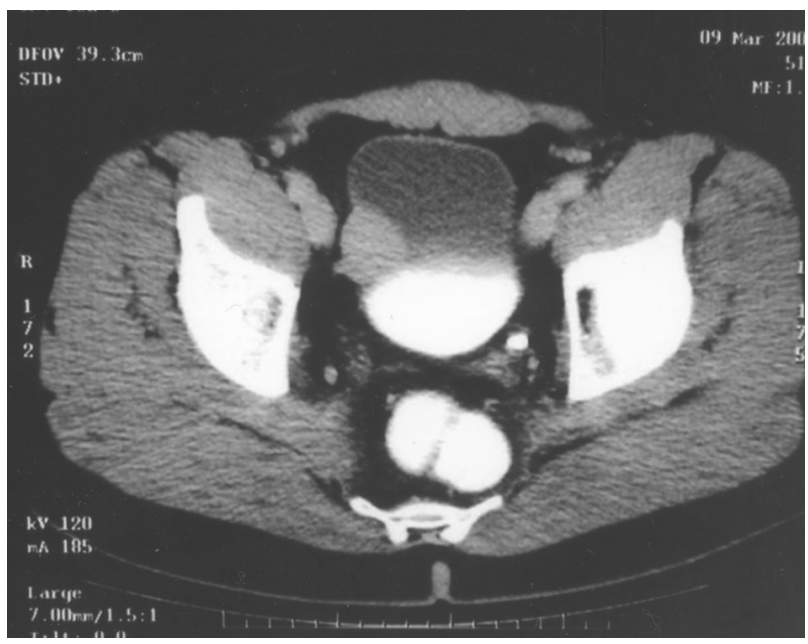

Figure 1 - Pelvic computerized tomography, showing tumor in right lateral wall of the bladder. 
findings. He underwent a cystoscopy, which showed a bulging in the right lateral wall of the bladder, without involving the mucosal surface, which presented normal aspect. The ureteral meatus were normal.

We performed a transurethral resection of the lesion. The pathological examination revealed a lymphoproliferative process with follicular pattern, characterizing a non-Hodgkin lymphoma of the bladder (Figure-2). The immunohistochemical analysis was positive to $\mathrm{CD} 20$, characterizing B-lymphocytes (Figure-3), and to bcL-2 protein (Figure-4), characterizing a follicular lymphoma. The patient was referred for adjuvant chemotherapy.

\section{COMMENTS}

Among cases of bladder lymphoma, approximately $17 \%$ occur in primary form, $47 \%$ in non-localized form, and $36 \%$ in secondary form (2). MALT-type lymphomas (mucosa associated lymphoid tissue) are the most common form of primary involvement of the bladder. The prognosis of these cases is usually good, and most series do not report deaths associated with the disease. The disease is 6.5 times more frequent in women and predominates in patients with mean age of 64 years old (20 to 85) (3). Lesions can be single or multiple, and irritative bladder symptoms may occur. Approximately $20 \%$ may present a history of chronic cystitis (2).

Cases of non-localized bladder lymphoma predominate in men, and tend to present fewer symptoms relative to bladder involvement. These patients usually present abdominal pain. Approximately half the patients can present ureteral obstruction. Mean survival in these cases is 9 years (2).

The occurrence of secondary involvement of the bladder by a systemic lymphoma is more common than primary involvement. Necropsy studies show that approximately 10 to $20 \%$ of cases of systemic nonHodgkin lymphoma can involve the bladder secondarily $(1,3)$. Normally, such patients die due to disseminated disease, which frequently involves other urogenital sites or associated with massive pelvic involvement.

In the series by Kempton et al. (2), 10 of 13 patients presented symptoms related to involvement

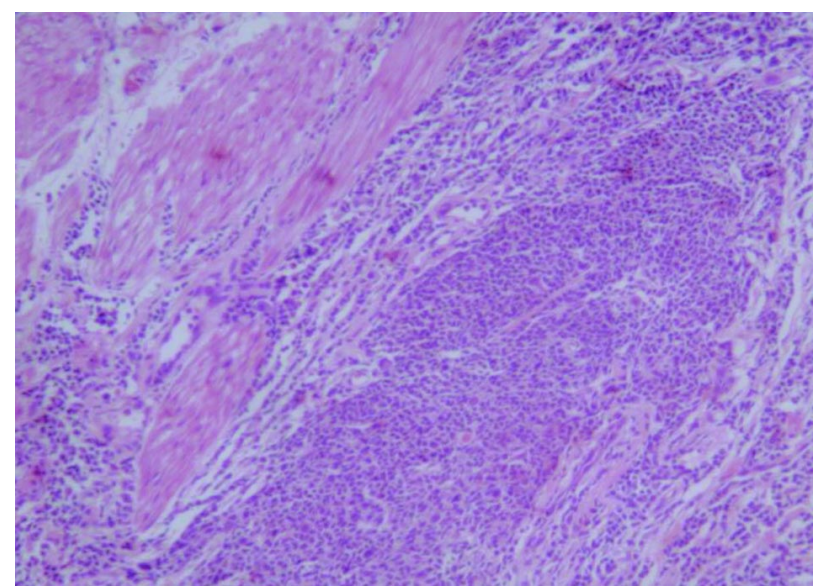

Figure 2 - Histological analysis of bladder wall showing lymphoproliferative process with follicular pattern (HE, X250).

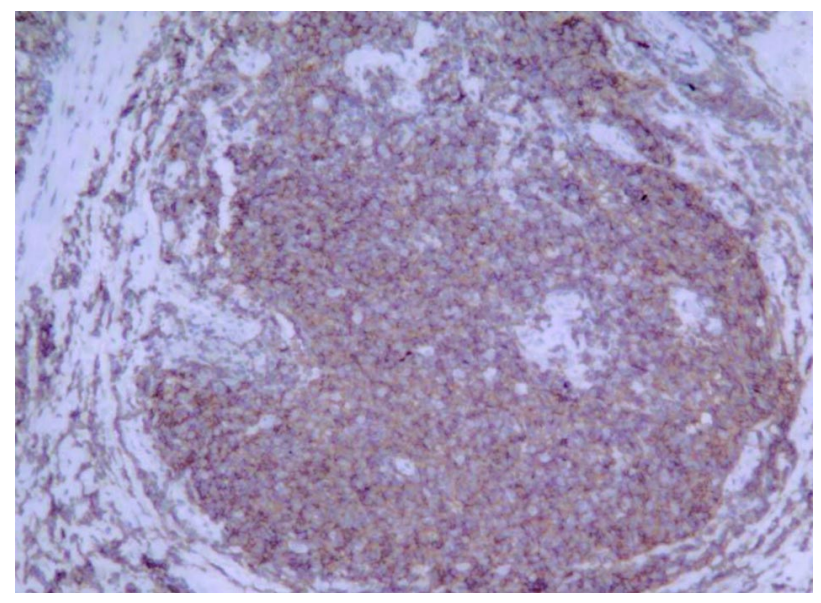

Figure 3 - Immunohistochemical positivity to CD20 (X400).

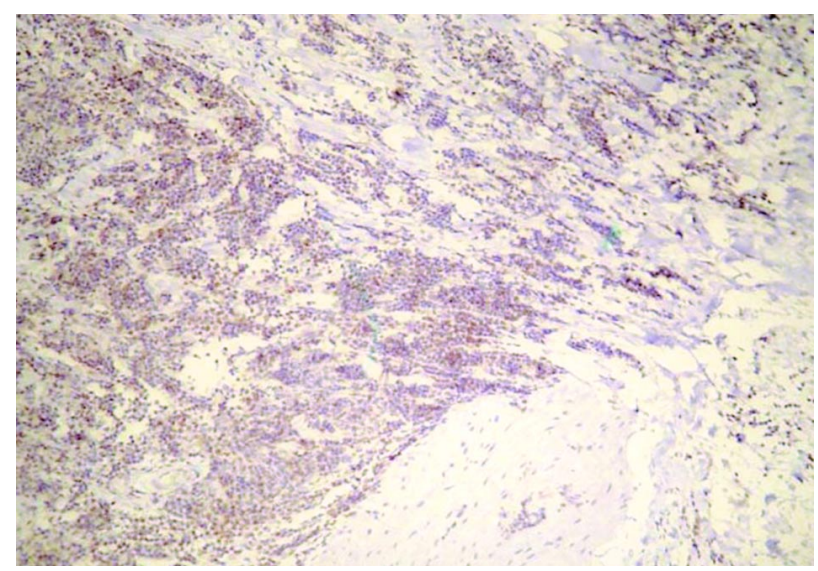

Figure 4 - Immunohistochemical positivity to bcL-2 protein, characterizing follicular lymphoma (X200). 
of the urinary tract, and $30 \%$ presented associated ureteral obstruction. The mean interval between diagnosis and secondary involvement of the bladder was 4.5 years ( 0.3 to 12 years), and the initial site of lymphomas, in decreasing frequency, were peripheral lymph nodes, bone marrow, spleen, orbit, lungs and palate. The patient in the present case presented initial involvement of lymph nodes from the cervical region.

Usually, patients with secondary involvement of the bladder are treated with salvage chemotherapy, and mean survival can range from 5 days to 8 years (median 0.58 years), thus constituting the group with poorer prognosis (2).

\section{REFERENCES}

1. Bates AW, Norton AJ, Baithun SI: Malignant lymphoma of the urinary bladder: a clinicopathological study of 11 cases. J Clin Pathol. 2000; 53: 458-61.

2. Kempton CL, Kurtin PJ, Inwards DJ, Wollan P, Bostwick DG: Malignant lymphoma of the bladder: evidence from 36 cases that low-grade lymphoma of the MALT-type is the most common primary bladder lymphoma. Am J Surg Pathol. 1997; 21: 1324-33.

3. Leite KRM, Bruschini H, Câmara-Lopes LH: Primary lymphoma of the bladder. Int Braz J Urol. 2004; 30 : 37-9.
Received: May 25, 2004

Accepted after revision: August 9, 2004

\footnotetext{
Correspondence address:

Dr. Luciano J. Nesrallah

R. Barata Ribeiro 414 / 25

São Paulo, SP, 01308-000, Brazil

E-mail: nesrallahuro@uol.com.br
} 